\title{
Safety Disconnect: Analysis of the Role of Labor Experience and Safety Training on Work Safety Perceptions
}

\author{
Esteban Lafuente $^{1}$ (iD), Jesús Abad ${ }^{1}$ (D), Yancy Vaillant ${ }^{2}$ iD \\ ${ }^{1}$ Universitat Politècnica de Catalunya (Spain), ${ }^{2}$ Toulouse Business School (TBS) (France) and Universidad de la Costa (Colombia) \\ esteban.lafuente@upc.edu,jesus.abad@upc.edu,y.vaillant@tbs-education.org
}

Received: October 2017

Accepted: January 2018

\begin{abstract}
:
Purpose: This study analyzes work safety perceptions among workers and safety experts in the construction industry. Furthermore, we evaluate whether experiential learning (i.e., labor experience) and knowledge-enhancing practices, that we link to safety training, explain the differences in work safety perceptions of workers and safety experts by triggering different types of overconfidence biases.

Design/methodology/approach: The proposed hypothesis are tested by applying ordered probit models on a unique dataset comprising information for 558 employees and 215 safety experts working in the Spanish construction sector.

Findings: The results reveal that previous labor market experience has a significantly negative effect on perceived work safety, that is, risk awareness decreases with respect to labor experience. However, the findings indicate that differences in perceived work safety between workers and safety experts are not explained by previous labor experience. Furthermore, the results suggest that higher levels of safety training, which we link to the acquisition of codified knowledge, negatively impacts workers' safety perceptions, while this effect turns positive among safety experts. This result suggests that safety experts' perceived work safety is affected by overconfidence that results from their greater safety-specific training (over-precision bias).

Originality/value: Work safety constitutes a relevant key performance indicator. The proposed analysis of the role of labor experience and safety training on perceived work safety in different types of employees contributes to better understand how organizations can improve the management of their workforce by triggering specific actions, such as the design of customized training programs, that may help in reducing the safety disconnect between employees, in terms of perceived work safety.
\end{abstract}

Keywords: safety disconnect, perceived work safety, overconfidence, over-estimation bias, over-precision bias, ordered probit model, workforce management

\section{Introduction}

Work safety has increasingly drawn scholarly and policy attention (e.g., Abad, Lafuente \& Vilajosana, 2013; Neal \& Griffin, 2006; Zohar, 2002). Overall, safety management is an important factor that should be included in the agenda of any organization as it contributes to improve the management of the workforce within the organization, reduce the number of occupational injuries and, ultimately, enhance business operations (Abad et al., 2013). The efficient analysis of occupational risks constitutes a critical aspect of work safety management (Porru, Placidi, Carta $\&$ Alessio, 2006). A deficient management of occupational risk assessments may lead to harmful consequences to 
workers, businesses, insurance companies and the society. According to the European Agency for Safety and Health at Work (EU-OSHA, 2013), the economic costs and operational losses of work accidents to workers, businesses, and public administrations represent 3\% of the EU's gross domestic product. The growing awareness of the importance of safety management has led European governing bodies to adopt specific policies within the EU 2020 strategic plan aimed at stimulating safe work conditions (European Commission, 2007).

From a business perspective, organizations suffer important losses as a result of poor safety management practices and work accidents. On the one hand, prior work emphasizes that the prioritization of safety management practices (e.g., adoption or development of safety systems or more rigorous safety controls) creates a safer work environment, which fulfills workers' safety needs and allows them to pursue operational goals (Das, Pagell, Behm \& Veltri, 2008). Also, increased safety controls may reduce operational losses linked to poor safety practices, such as unpredicted production breaks, absenteeism and labor turnover, and this will likely impact economic performance (Abad et al., 2013; Lafuente \& Abad, 2018). On the other hand, in the US, conservative estimates point to nearly 6 million occupational injuries and 6,000 fatalities per year which cost about 140 billion dollars (Porru et al., 2006). Therefore, efficient safety management practices are needed to reduce accidents and their economic costs as well as the number of nonproductive downtime hours which may well result in higher productivity and improved business performance (Abad et al., 2013; Rodríguez-Garzon, Lucas-Ruiz, Martínez-Fiestas \& Delgado-Padial, 2014).

Training programs (formal encoded knowledge) and greater labor experience (experiential knowledge) are often invoked as solutions to improve work safety conditions (e.g., Hung, Winchester, Smith-Jackson, Kleiner, Babski-Reeves \& Mills, 2013; Perlman, Sacks \& Barak, 2014). Nevertheless, organizations do not realize the generally positive effects of these types of knowledge. This is the core of this study. We argue that both employees and safety experts carry out different operational tasks and are exposed to different work risks which create a safety disconnect, defined in terms of the discrepancies in work safety perceptions between workers and safety experts. More concretely, this study scrutinizes work safety perceptions among workers and safety experts in the construction industry. Furthermore, we evaluate whether experiential learning (i.e., labor experience) and knowledge-enhancing practices, that we link to safety training, explain the differences in work safety perceptions of workers and safety experts by triggering different types of overconfidence biases.

The empirical application uses a unique dataset comprising information for 558 employees and 215 safety experts working in the Spanish construction sector. The proposed analysis of the role of labor experience and safety training on perceived work safety in different types of employees contributes to our understanding on how organizations can improve the management of their workforce by triggering specific actions linked to the design of customized training programs that may help in reducing the discrepancies between safety experts and employees (i.e., the safety disconnect) in terms of perceived work safety.

The remainder of the paper is structured as follows. Section 2 presents the theoretical underpinning and the study hypotheses. In section 3 the sample, variables and the method are presented. Empirical results are found in Section 4 , while the final section provides the concluding remarks and implications.

\section{Background Theory and Hypotheses Development}

\subsection{Work Safety Management and Perceived Work Safety}

A good starting point for this section is to question 'what is risk?' Work risks have been studied by many scholars in different disciplines from engineering (Rodríguez-Garzon et al., 2014; Rundmo, 2000; Sjöberg, 2000) to philosophy (Zohar \& Luria, 2005). Traditionally, risk is defined as a qualitative (subjective) construct that includes the likeliness of hazard and its potential consequences (in terms of work accidents) (Fischhoff, Slovic, Lichtenstein, Read \& Combs, 1978; Rundmo, 2000).

Two groups of factors characterize risk: 1) dread, as the extent to which a hazard causes feelings of fear (related to lack of control, dreaded consequences, catastrophic potential and fatal consequences), and 2) obscurity, as a level of risk understanding (related to knowledge, immediacy of consequences, newness and observability) (Portell, Gil, Losilla \& Vives, 2014). Therefore, work risk assessments include hazard identification, risk characterization, risk level assessment, evaluation of the probability of occurrence and expectations about severity of accidents (Porru et 
al., 2006). Hazard identification and risk awareness are the first steps in safety management practices oriented to enhance employees' perceived safety (Perlman et al., 2014).

Because of its subjective evaluation, risk awareness and perceived work safety have been studied by psychologists and sociologists using both qualitative and quantitative approaches. The dominant approach in this field is the psychometric paradigm which assumes risk as subjectively defined by individuals who can be influenced by a wide array of psychological, social, institutional and cultural factors (Portell et al., 2014). Hallowell (2010) defines risk perception as an individual's subjective judgment of the frequency and severity of a particular danger.

In parallel to this research stream, another important dimension of safety management relates to perceived work safety. Prior studies argue that perceived work safety is, to a certain extent, shaped by organizational factors (e.g., work safety climate) and that greater average levels of perceived safety are associated with fewer work accidents (Arcury, Summers, Rushing, Grzywacz, Mora, Quandt et al., 2015; Huang, Verma, Chang, Courtney, Lombardi, Brennan et al., 2012). Thus, safety climate is the collective outcome of individual workers' perceptions about organizational policies and practices which they relate to the value and importance of safety within the business (Griffin \& Neal, 2000; Zohar, 2002, 2003).

Note that safety climate has two dimensions: the shared-group safety climate and the individual psychological safety climate (Christian, Bradley, Wallace \& Burke, 2009). The group-level safety climate is defined as shared perceptions of the work environment and characteristics as they pertain to safety matters that affect a group of individuals, while the psychological safety climate is the individual perception of safety-related policies, practices, and procedures that affect personal well-being at work (Huang et al., 2012). The individual safety climate, which is linked to perceived work safety, is the focus of this study.

The relevance of balancing internal practices, which are an antecedent of business productivity, with work safety flows from the recognition that perceived work safety is a time-varying construct that interacts with other (operational and organizational) factors seeking increased levels of adaptation to operational and environmental changes and, ultimately, shape the organizations' safety system (Woods, 2015; Niskanen, 2018). These arguments are in consonance with postulates of the Resilience Engineering theory that emphasizes the relevance for the business' operational and safety system of harmonizing work environmental conditions with safety practices (Patriarca, Bergström, Di Gravio \& Costantino, 2018). Underlying this literature is the presumption that organizations are systems whose level of complexity results from the interactions between its constituent components (e.g., organizational, operational, safety-related). In this sense, resilience engineering deals with the evaluation of the functioning of complex systems, including risk determinants and the factors that affect human performance, to provide systems engineering tools that contribute to manage risks proactively (Niskanen, 2018; Patriarca et al., 2018).

The significance of improving workers' perceived safety is based, among other things, on the need to increase self-protective and safety behaviors (Neal \& Griffin, 2006; Zohar \& Luria, 2005). Also, low levels of perceived work safety potentially create stress, and this leads to unsafe behaviors at work (Rundmo, 1996). Following this line of reasoning, Hallowell (2010) finds that the number of work accidents is highly correlated with the violation of safety standards. Perlman et al. (2014) state that work accidents may originate from carelessness or lack of risk awareness on the part of workers. However, other researchers show that accidents are not primarily caused by workers' risk awareness but rather by management failures (Baxendale \& Jones, 2000).

In this sense, the capacity of management to accurately describe work tasks as they are actually carried out, rather than as usually described in operating procedures or static models, largely contributes to create/develop the employees' capability to cope with complex, adaptive systems (De Carvalho, Righi, Huber, Lemos, Jatoba \& Gomes, 2018). Therefore, monitoring and understanding the gap between prescription (or work as imagined) and practice (or work as done) is critical for the effective design of managerial and safety systems (Braithwaite, Wears \& Hollnagel, 2017).

Among the factors under the control of the employer, safety training is often invoked as an efficient mechanism for improving workers' risk assessment and perceived safety level. Training is needed to achieve effective levels of hazard perception and to reduce work accidents (Rodríguez-Garzon et al., 2014). Additionally, the effectiveness of 
training methods heavily relies on its capacity to narrow the gap between work-as-imagined and work-as-done by reflecting the reality of job tasks performed by employees, as well as to allow space for constant improvement of theoretical and formal aspects of work operations, which can be guided by tacit or contextual knowledge developed through day-to-day work experiences (De Carvalho et al., 2018). Zimolong and Trimpop (1998) propose that workers' experience and training contribute to improve work safety perceptions via enhanced identification of work risks. In summary, the perception of work safety is malleable (Starren, Hornikx \& Luijters, 2013). Various studies show that perceived work safety can be improved by exploiting both prior experience on work accidents (Gucer, Oliver \& McDiarmid, 2003; Mearns, Flin, Gordon \& Fleming, 1998) and the workers' labor experience (Mohamed, Ali \& Tam, 2009).

Perceived work safety is a highly subjective construct (Gierlach, Belsher \& Beutler, 2010), and differences in safety-specific knowledge may explain variations in this variable. So can a person's involvement in the day-to-day operations of a business.

Furthermore, perceived work safety is also heterogeneous across the different types of employees working for the organization (Fischhoff et al., 1978; Portell et al., 2014). While employees are more familiar with the different work risks and have experienced (or witnessed) work accidents, safety experts who design and implement safety measures may have a different mindset regarding safety at work (Perlman et al., 2014). This may amplify the gap between work-as-imagined and work-as-done among safety experts compared to workers and, ultimately, affect the effectiveness of work safety measures (De Carvalho et al., 2018).

We argue that experiential knowledge generates valuable tacit know-how among workers and that this shapes their safety perceptions, while safety experts' perceived safety is primarily driven by formal and codified safety knowledge associated with the more academic nature of their human capital (Huang et al., 2012). Both sources of knowledge are equally valuable; however, risk assessments can significantly vary as a result of differences in knowledge and in self-confidence biases linked to knowledge acquisition processes. The factors affecting perceived safety are not yet sufficiently evaluated, and this study seeks to explore how different sources of knowledge contribute to explain variations in work safety perceptions among safety experts, who design and coordinate work safety plans and strategies and workers, who execute work safety practices within the organization.

\subsection{Overconfidence}

Overconfidence is a complex concept that has been widely studied. The phenomenon of overconfidence may represent a driving force for engaging in various positive behaviors, including entrepreneurship entry decisions (e.g., Hogarth \& Karelaia, 2012; Lafuente, Vaillant \& Rialp, 2007) or enhanced safety behavior (Zohar, 2002; Zohar \& Luria, 2005). But, overconfidence may also have negative consequences, such as strikes, litigation or entrepreneurial failure (Howard, 1983; Camerer \& Lovallo, 1999; Malmendier \& Tate, 2005; Neale \& Bazerman, 1985). People behavior is susceptible to the influence of overconfidence, especially in the decision-making and judgments and there is the greatest danger behind it, as overconfidence can lead to significant negative consequences (Plous, 1993: page 217).

Scholars have traditionally studied overconfidence as a homogenous construct. Nevertheless, Moore and Healy (2008: page 502) emphasize that overconfidence is heterogeneous, and identify three different types of overconfidence: overestimation of one's actual capacities, over-placement or better-than-average, and over-precision.

The overestimation in one's actual capacities refers to the person's inflated perception of his/her abilities, performance, level of control, or chances of success. For example, the overestimation of one's own entrepreneurial abilities has been found to explain both excess entrepreneurial entry and failure (Hogarth \& Karelaia, 2012). Over-placement or better-than-average bias appears when people believe themselves to be better than the majority at any focal task (such as when a majority of people rate themselves better than the median at any task). Overprecision represents the excessive certainty regarding the accuracy of one's beliefs. A typical test of over-precision is to ask respondents a numerical question, for example, 'How many cities there are in the world?' and then give participants the opportunity to provide $90 \%$ confidence interval estimates around their answers. Narrow 
confidence intervals would suggest that people are too sure about their answer; while wide confidence intervals are evidence of lack of confidence in the answer (Klayman, Soll, Gonzalez-Vallejo \& Barlas, 1999; Soll \& Klayman, 2004).

Moore and Healy (2008) propose that people's beliefs results from the analysis of two components: the global average result of others and the individual's own performance. Also, task performance experience gives individuals valuable knowledge and signals about their results: has it been done well or bad and how much (Argote \& Miron-Spektor, 2011). Furthermore, people benchmark themselves to predict others' outcomes and consider these results useful (Krueger, Acevedo \& Robbins, 2005).

Nevertheless, people have imperfect information about their own performance, abilities, or chance of success; and they have even worse information about others (Moore \& Healy, 2008). As a consequence, people's estimates of themselves are regressive, and their estimates of others are even more regressive. So far, we have argued that people make imperfect estimates of their own performance; the more familiar the focal problems is, the better information people have about their performance; and that people have superior information about themselves within their group rather than about other people outside their group.

Overall, this theory can be applied to different phenomena like for example individual performance, deductions about abilities as well as behaviors and traits. Furthermore, these arguments can prove themselves useful to evaluate the effect of experience and formal knowledge on perceived safety. This latter point is the focus of this study.

In our approach, different types of workers develop different types of overconfidence which creates variations in the perception about work safety. While employees acquire and develop experiential knowledge linked to their day-to-day tasks, safety experts-who may not be familiar with the work environment-acquire specific safety codified knowledge that guides their safety perceptions and evaluations. We believe that this creates a safety disconnect between workers' and safety experts' perception of safety that is worth studying.

\subsection{Safety Disconnect and Hypothesis Development}

This study examines whether there is a disconnection between workers' and technicians' perception of safety at work and, if so, whether different types of knowledge explain this safety disconnect.

Fischhoff et al. (1978) show that there are significant differences between non-experts' views on safety and experts' statements because, unlike experts, non-experts evaluate risks intuitively, informally and less precisely. In their analysis, Portell et al. (2014) find that participants (employees) gave a greater valuation to their own safety knowledge relative to that of safety experts (the questions about the expert knowledge were characterized as the knowledge of health and safety by managers of the company). This is in line with our arguments that experts have superior safety-specific knowledge than workers. Prior work has analyzed differences in safety perceptions using various factors, such as work environment (Reisinger \& Mavondo, 2005); demographic aspects (Björk, Lindqvist, Poukkula, Ravald, West \& Åhman, 2004; Boix, García, Llorens \& Torada, 2001; Sjöberg, 2000); and emotional conditions, such as fear, anger, or stress (Grasmück \& Scholz 2005). Results are mixed. Moreover, Rodríguez-Garzon et al. (2014) found that among all socio-demographic elements only training explains differences in people's safety perceptions.

Huang et al. (2012) propose that workers and safety experts working for the same organization may have similar safety perceptions because workers' individual safety perceptions are developed, estimated, and prioritized by observing those of supervisors. On the other hand, safety experts and employees are different as the former group designs and implements safety policies and procedures and conduct safety training for employees, while the latter group receives the training and observe how experts implement safety policies and procedures. Huang et al. (2012) also found that safety perceptions were not consistent between safety supervisors and employees because they may have had different opportunities to observe and evaluate safety performance at the workplace. This result suggests that differences in the origin of safety knowledge may lead to a safety disconnect, in terms of safety perceptions, between safety experts and employees, even if both groups work for the same organization. Hung et al. (2013) reveal that workers perceive that their safety knowledge is high, and that workers do not value working safely due to the presence of a strong overconfidence bias. 
Despite the rigorous efforts, these studies do not identify the source of the differences in work safety perceptions (Portell et al., 2014). In this study, we propose that the safety disconnect between workers and experts, in terms of perceived work safety, can be explained by the differentiating effect of labor experience and formal training over safety perceptions. In our view, different types of overconfidence may influence workers and safety experts which may explain the observed differences in safety perceptions.

For both workers and safety experts, work safety perceptions are not only subjective, but also shaped by their own beliefs, knowledge, and experience.

In the case of workers, safety knowledge is primarily driven by task-performance experience and, in their work roles, they often have to choose between higher level of safety and better performance (Abad et al., 2013; Caponecchia \& Sheils, 2011). The differential value of productivity results associated with less use of personal protective equipment (PPE) and greater unsafe behaviors are associated with lower productivity levels (Arcury, Summers, Carrillo, Grzywacz, Quandt \& Mills, 2014). For example, Arcury et al. (2015) report that Latino construction workers prioritize productivity over work safety mostly due to employment needs, comfort preferences and the created belief that their knowledge leads to better decision-making which minimizes potential work accidents. That is, from their experiential knowledge workers underestimate some risks (poor risk awareness) and overestimated own abilities. Therefore, it seems plausible to argue that workers may develop overconfidence due to the overestimation of their own actual capacities.

Concerning safety experts, their safety knowledge mostly results from formal specific sources (university, specific courses, training), and they prioritize workplace safety conditions. In this case, we argue that safety experts' superior formal knowledge yields to overconfidence due to the over-precision (excessive certainty) regarding the accuracy of their estimations. For example, Porru et al. (2006) highlight the increased safety awareness among managers and safety experts as workers do not have the knowledge to accurately value all work risks. Perlman et al. (2014) suggest that, even after many years of experience, construction workers and superintendents were unable to identify all hazards at the site; and that they give a greater weight to risk levels in their assessments based on accident severity considerations, instead of the probabilistic component of risk.

This theory and evidence suggests that there is a safety disconnect in the safety perceptions of safety experts and workers, and that this disconnect may originate from knowledge-based differences that translate in different overconfidence bias. From these arguments, we therefore hypothesize:

H1: Among workers, perceived safety at work is influenced by overconfidence arising from greater labor experience (overestimation bias)

H2: Among safety experts, perceived safety at work is affected by overconfidence that results from their greater formal safetyspecific training (over-precision bias)

\section{Data, Variable Definition and Method}

\subsection{Data}

The empirical illustration of this study uses a unique dataset on work safety. The questionnaire employed in this work was designed specifically for the purposes of this study, and the data collection process was entirely designed, implemented and supervised by a team of the Barcelona School of Building Construction (EPSEB) at the Polytechnic University of Catalonia (UPC BarcelonaTech). The information was collected between the last quarter of 2010 and the first quarter of 2011 by applying the questionnaire to construction workers and safety experts working in the construction industry.

Construction workers and safety experts working in the construction industry were approached at the construction site, or in their office in the case of some safety experts, with a request to participate in the study in the form of a brief talk where the team member explained the purposes and the strictly scientific scope of the study. Also, in this initial stage participants received confirmation on confidentiality. Once the team member obtained the respondents' approval, data collection was achieved through self-administrated, structured face-to-face interviews where construction workers and safety experts were asked to answer essentially close questions. It should be kept in mind 
that, following the practice recommended in the literature (Colton \& Covert, 2007), the questionnaire was also subject to a pre-test in order to correct potentially misleading or confusing questions.

The original data base comprises information for 799 individuals (584 construction workers and 215 safety experts). However, in the interest of following a rigorous methodology that ensures the robustness of the results, only observations for which a complete dataset of the analyzed variables could be obtained were included. Thus, we excluded 26 cases, all construction workers, with incomplete data due to the refusal or unawareness of the respondent to answer questions mostly related to their perceived level of work safety, the number of hours of safety training in their personal record, and their relationship with co-workers. Therefore, the final sample includes information for 773 individuals of which 558 are constructions workers and 215 are safety experts.

\subsection{Variable Definition}

Perceived safety at work. In this study, the dependent variable measures the perceived level of work safety among the surveyed employees and supervisors. Both employees and safety supervisors were asked along a five-point Likert scale to value the safety level at their workplace $(1=$ not at all dangerous and $5=$ extremely dangerous) (question: On a scale of 1 (not at all dangerous) to 5 (extremely dangerous), how do you evaluate the level of hazardousness of the tasks you develop within the organization?). The frequency distribution in Table 1 shows that the greatest proportion of respondents perceive their workplace as 'moderately dangerous' and 'very dangerous' (34.93\%). A more in-depth examination reveals that experts perceive greater risks at work than workers: $82.79 \%$ of experts perceive that their workplace is 'moderately dangerous' or a 'very dangerous', whereas this proportion stands at $64.88 \%$ among workers.

Additionally, $15.01 \%$ of respondents indicate that their workplace is 'extremely dangerous'. The proportion of workers who manifest to work in an 'extremely dangerous' place is greater $(16.67 \%)$ relative to that of experts $(10.70 \%)$. Furthermore, respondents falling into the 'not at all dangerous' and 'slightly dangerous' categories account for $15.14 \%$ of the full sample, and the proportion of workers who positively valued safety at work $(18.36 \%)$ more than doubles that found for supervisors $(6.52 \%)$.

\begin{tabular}{|l|r|r|r|r|r|}
\hline & \multicolumn{1}{|c|}{$\begin{array}{c}\text { Not at all } \\
\text { dangerous } \\
\text { (1) }\end{array}$} & \multicolumn{1}{|c|}{$\begin{array}{c}\text { Slightly } \\
\text { dangerous } \\
\text { (2) }\end{array}$} & $\begin{array}{l}\text { Moderately } \\
\text { dangerous } \\
\text { (3) }\end{array}$ & $\begin{array}{c}\text { Very } \\
\text { dangerous } \\
\text { (4) }\end{array}$ & \multicolumn{2}{|c|}{$\begin{array}{c}\text { Extremely } \\
\text { dangerous } \\
\text { (5) }\end{array}$} \\
\hline Observations & 33 & 84 & 270 & 270 & 116 \\
\hline Proportion & $4.27 \%$ & $10.87 \%$ & $34.93 \%$ & $34.93 \%$ & $15.01 \%$ \\
\hline
\end{tabular}

Table 1. Frequency table of perceived safety at work

Accumulated knowledge. We use two variables to measure accumulated knowledge. First, we include the total years of labor experience, expressed in years. Second, we employ the number of hours of formal safety training to measure the specific safety knowledge accumulated by individuals (employees and safety experts). Average labor experience is 10 and 11 years for safety experts and workers, respectively. The significant discrepancy lies in the safety training. We found that the sampled technicians (safety experts) have, on average, 242 hours of safety training, while for workers this value stands at 21 hours. This result only reflects the differences in training standards. Construction workers are not required to have specific safety training, and this becomes evident in our sample: 17.38\% (97) of the sampled workers reported no prior safety training, while $27.96 \%$ (156 workers) chose to attend a safety training program (for this group, the training course has a duration of between 30 and 300 hours). Because their tasks and decision-making are critical to ensure compliance with applicable safety practices and regulations, formal (certified) knowledge is required to safety experts. The descriptive results in Table 2 are in line with this notion: 49.77\% (107) of safety experts attended the basic safety course of 30 hours, $21.86 \%$ (47) took the safety training course of 300 hours, while $28.37 \%$ (61) safety experts attended the 600 hours course.

Control variables. We control for the perceived level of working load, work interruptions, and the relationship with co-workers in our model specifications. Perceived level of working load measures the individual perception of 
amount, intensity, difficulty as well as occupational stress. Both employees and safety supervisors were asked along a four-point Likert scale to value the perceived level of workload ( $1=$ not at all busy and stressed, $2=$ moderately busy and stressed, $3=$ very busy and stressed and $4=$ extremely busy and stressed) (question: On a scale of 1 (not at all busy and stressed) to 4 (extremely busy and stressed), how would you rate your current workload?). Also, we introduced a dummy variable taking the value of one if the person considers that he/she is frequently interrupted by others (co-workers, managers, etc.) or work-related events (e.g. unexpected meetings, accidents, etc.). Finally, we introduced a variable that measures the relationship with co-workers (question: how would you evaluate your personal relationship with your co-workers?). This variable was measured via a five-point Likert scale $(1=$ not at all good and 5= extremely good).

\begin{tabular}{|l|c|c|c|}
\hline & Workers & Safety experts & Full sample \\
\hline Perceived safety at work & $3.3961(1.0765)^{* * *}$ & $3.6093(0.8006)$ & $3.4554(1.0114)$ \\
\hline Labor experience (years) & $11.18(10.02)$ & $9.98(9.82)$ & $10.85(9.97)$ \\
\hline Safety training (hours) & $21.26(29.54)^{* * *}$ & $241.95(252.86)$ & $82.64(167.77)$ \\
\hline Perceived level of working load & $2.5556(0.7833)^{* *}$ & $2.7581(0.9653)$ & $0.4373(0.4964)$ \\
\hline Work interruptions & $0.3620(0.4810)^{* * *}$ & $0.6326(0.4832)$ & $3.8163(0.7818)$ \\
\hline Relationship with co-workers & $3.7724(0.7533)^{* *}$ & $3.9302(0.8427)$ & 773 \\
\hline Observations & 558 & 215 & $0.8422)$ \\
\hline
\end{tabular}

Standard deviation is presented in brackets. *, **, *** indicate that, for each variable, the valuation made by workers and supervisors is significantly different at the $10 \%, 5 \%$, and $1 \%$, respectively.

Table 2. Descriptive statistics for the selected variables

\subsection{Method}

Similar to other multinomial-choice variables analyzed in previous research dealing with safety issues (e.g., injury severity of car crashes and work accidents), work safety perceptions are inherently ordered (see the recent survey of Savolainen, Mannering, Lord \& Quddus, 2011). Therefore, an ordered probit model was chosen as econometric tool to test the proposed hypotheses that emphasize the role of labor experience (H1) and formal training (H2) on the level of perceived work safety among employees and technicians (Greene, 2003).

The ordered probit model is built around a latent regression of the form $y^{*}=\beta \mathbf{x}^{\prime}+\varepsilon$, where $y^{*}$ is the latent unobserved dependent variable (perceived safety at work), $\mathbf{x}^{\prime}$ is the vector of variables determining the discrete ordering for each observation, $\beta$ is the vector of parameter estimates, and $\varepsilon$ is the normally distributed error term (Long, 1997). In this study, respondents choose the category that most closely represents their own perception on work safety conditions (Table 1). The ordered probit model that defines each category of the variable linked to perceived safety at work $(j=1, \ldots, 5)$ has the following form:

$$
\begin{array}{lll}
\mathrm{y}_{j=1}=1 & \text { if } & y^{*} \leq \mathrm{u}_{1} \\
\mathrm{y}_{j=2}=2 & \text { if } & \mathrm{u}_{1} \leq y^{*} \leq \mathrm{u}_{2} \\
\mathrm{y}_{j=3}=3 & \text { if } & \mathrm{u}_{2} \leq y^{*} \leq \mathrm{u}_{3} \\
\mathrm{y}_{j=4}=4 & \text { if } & \mathrm{u}_{3} \leq y^{*} \leq \mathrm{u}_{4} \\
\mathrm{y}_{j=5}=5 & \text { if } & y^{*} \geq \mathrm{u}_{4}
\end{array}
$$

In equation (1) $u_{j}$ are unknown parameters that are estimated jointly with $\beta$. Coefficients estimated by discrete choice models, including ordered probit specifications, indicate the direction of the effect of the analyzed variable on the dependent variable. In this study, the full model estimated via ordered probit model has the following form: 
Perceived

work safety $_{i}=\beta_{0}+\beta_{1}$ Worker $_{i}+\beta_{2}$ Labor experience $_{i}$

$+\beta_{12}$ Woker $_{i} \times$ Labor experience $_{i}+\beta_{3}$ Safety training $_{i}$

$+\beta_{13}$ Woker $_{i} \times$ Safety training $_{i}+\beta_{4}$ Controls $_{i}+\varepsilon_{\mathrm{i}}$

In terms of our hypotheses, we expect that $\beta_{12} \neq 0$, that is, workers' perceived work safety is influenced by overconfidence (over-estimation bias) arising from greater labor experience $(\mathbf{H 1})$. We also expect that $\beta_{13} \neq 0$, that is, among safety experts perceived work safety is affected by overconfidence that results from their greater formal safety knowledge (H2: over-precision bias).

\section{Results}

This section presents the results of the empirical analysis. In Table 3, model specification 1 is the baseline model, while model 2 is the full model that includes the interaction terms between the 'worker' dummy and the different sources of knowledge and experience analyzed in this study (equation (2)). Note that the dependent variable in this analytical section is the level of perceived safety at work. To evaluate the threat of collinearity, we computed the average inflation factor (VIF) for all independent variables. In all model specifications presented in Table 3, the VIF values are below the commonly used cut-off threshold of ten. The results for this diagnostic test do not raise collinearity concerns.

Concerning the key findings of the study, regression results in Table 3 show that there is a disconnection between workers and safety experts, in terms of perceived work safety; however, this disconnection only becomes evident when we take into account the differentiating effect of variables related to accumulated knowledge and experience in the model (model 2).

The results in model 1 (Table 3) reveal that previous labor market experience has a significantly negative effect on perceived work safety, that is, risk awareness decreases with respect to labor experience. Nevertheless, from model specification 2 we observe that differences in perceived work safety between workers and safety experts are not explained by previous labor experience in a significant way. This result suggests that labor experience, which we associate to task repetition, generates experiential learning that is detrimental to safety evaluations, and that this process may create a perception of 'naïve safety' that affects both construction workers and safety experts.

Therefore, we do not find support for our first hypothesis that states that, among construction workers, perceived safety at work is influenced by overconfidence arising from greater labor experience (over-estimation bias) (H1).

The results for the safety training variables in model 1 indicate that this variable solely does not influence individual risk assessments that translate in different levels of perceived work safety.

Nevertheless, the findings for the full model that includes the interaction between the 'worker' dummy and safety training points to the presence of a differentiated effect of safety training on workers' and experts' work safety perceptions. From model 2 in Table 3 we note that the coefficient for the safety training variable is positive and statistically significant, that is, increased safety training (in terms of hours) yields to superior awareness about the potential risks at work among safety experts, thus conditioning their assessment of work safety conditions.

On contrary, the result for interaction term between the 'worker' dummy and the safety training variable show that higher levels of safety training, which we link to the acquisition of codified knowledge, negatively impacts workers' safety perceptions. These results, that suggest a somewhat contradictory effect of safety training programs on work safety perceptions, are in line with our second hypothesis $(\mathbf{H} 2)$ that states that, among safety experts, perceived work safety is affected by overconfidence that results from their greater safety-specific training, formal knowledge, (over-precision bias). 


\begin{tabular}{|l|c|c|}
\hline & Model 1 & Model 2 \\
\hline Worker & $-0.1903(0.1367)$ & $0.6731(0.3873)^{*}$ \\
\hline Labor experience & $-0.2089(0.0757)^{* * *}$ & $-0.0758(0.1119)$ \\
\hline Labor experience X Worker & & $-0.1388(0.1482)$ \\
\hline Safety training (ln hours) & $0.0362(0.0313)$ & $0.1164(0.0334)^{* * *}$ \\
\hline Safety training X Worker & & $-0.2167(0.0708)^{* * *}$ \\
\hline Perceived level of working load & $0.2730(0.0745)^{* * *}$ & $0.2884(0.0759)^{* * *}$ \\
\hline Work interruptions & $0.1541(0.1387)$ & $0.1412(0.1393)$ \\
\hline Relationship with co-workers & $0.0314(0.0852)$ & $0.0439(0.0851)$ \\
\hline Cut 1 & $-2.7473(0.5091)^{* * *}$ & $-2.1399(0.5480)^{* * *}$ \\
\hline Cut 2 & $-1.3463(0.4820)^{* * *}$ & $-0.7336(0.5261)$ \\
\hline Cut 3 & $0.4313(0.4808)$ & $1.0587(0.5246)^{* * *}$ \\
\hline Cut 4 & $2.2115(0.4899)^{* * *}$ & $2.8561(0.5325)^{* * *}$ \\
\hline Log pseudolikelihood & -1062.95 & -1057.61 \\
\hline Wald test (chi2) & $35.30 * * *$ & $46.70 * * *$ \\
\hline Pseudo R2 & 0.0453 & 0.0524 \\
\hline Average VIF (min - max) & $1.07(1.01-1.16)$ & $3.68(1.03-9.66)$ \\
\hline Observations & 773 & 773 \\
\hline Robust stan & & \\
\hline
\end{tabular}

Robust standard errors adjusted by heteroskedasticity are presented in brackets. *, **, *** indicates significance at the $10 \%, 5 \%$ and $1 \%$, respectively.

Table 3. Ordered probit model: Perceived safety at work

\section{Concluding Remarks, Implications and Future Research Lines}

In this study, we propose that discrepancies exist in the work safety perceptions of construction workers, compared to those of safety experts. More concretely, we hypothesized that different types of overconfidence linked to experiential learning (labor experience) in the case of workers, and to greater formal safety knowledge among safety experts may shape the perceptions about work safety conditions.

Overall, this study provides further evidence that contributes to understand how organizations can improve their safety training programs in order to enhance the management of their workforce. Additionally, results reveal that the effects of accumulated knowledge and experience over perceived work safety are heterogeneous across workers. We argue that discrepancies may arise from differences in overconfidence that may condition the coupling of knowledge-generating efforts to individuals' risk assessments. On the one hand, we found that, among workers and safety experts, greater labor experience does not lead to over-estimation bias when it comes to work risk assessments. On the other hand, greater formal knowledge on work safety conditions increases the over-precision bias among safety experts, which modifies their work safety perceptions by increasing their risk awareness.

This paper has implications for scholars and practitioners. From an academic perspective, the results show that different types of knowledge (i.e., experiential knowledge resulting from labor experience and specific codified knowledge linked to formal training) may initiate different reactions among workers and safety experts by generating different types of overconfidence. Overconfidence can be a driving force for engaging in various positive behaviors, including the assessment of work risks. However, knowledge generation/acquisition processes may also lead to less desirable effects over overconfidence (Plous, 1993), such as poor risk awareness. Our analysis of the role of different forms of knowledge on perceived work safety contributes to a better understanding of the conditions under which the effects of learning-enhancing strategies occur within businesses. Similar to Moore and 
Healy (2008), this study shows that overconfidence is a multi-dimensional concept, and future research should evaluate the potentially differentiating effects of different policies and actions on the overconfidence level of the targeted subjects (e.g., workers, safety experts, managers, directors). Additionally, the results of the study provide new evidence on the presence of 'naive empiricism' among workers (Juslin, Winman \& Olsson, 2000). The findings suggest that workers' empirical dogmatism may negatively influence the effect of safety training over perceived work safety.

Knowledge generation and exploitation processes, such as training programs, are potentially conducive to business success; however, these processes will not produce the desired effects if a misalignment between organizational practices and the workforce exists. Therefore, for strategy makers we first suggest that managers need to turn their attention to the characteristics of specific training programs oriented to improve safety knowledge among employees and, consequently, work safety conditions. Many organizations promote training programs seeking to improve the knowledge base of their workers. Nevertheless, the quick implementation of training programs is not enough. Training programs should not be treated as a monolithic concept common to all types of employees. Workers and safety experts are exposed to different types of risks at their work places, and the different characteristics of the operational contexts where employees develop their tasks calls for a profound analysis of training programs. A greater alignment between the different types of employees, in terms of perceived work safety, is especially relevant in the case of construction organizations in which the work conditions of construction sites are subject to significant variations across projects.

In this sense, managers would be well advised to analyze the characteristics of work tasks before promoting training programs. Thus, any attempt to promote workers' learning via training should be coupled with enhanced strategic analyses that acknowledge the different operational realities faced by employees. The design of customized training programs therefore constitutes a valid option that will likely contribute both to optimizing the potentially positive outcomes of knowledge generation practices, such as training programs; and to reduce the safety disconnect between workers and its potential negative operational consequences.

A series of limitations to the present study must, however, be mentioned. These limitations, in turn, represent future research lines. First, like other studies on safety management (e.g., Perlman et al., 2014; Zohar \& Luria, 2005), the data do not permit the direct analysis of the underlying mechanisms that trigger the safety disconnect between workers and safety experts. We present various interpretations of how risk awareness is driven by different types of knowledge (tacit or formally codified); however, we do not evaluate how shared beliefs between workers and safety experts shape risk assessments, nor do we assess the processes through which perceived work safety generate. Further research can address this point by evaluating whether perceived work safety varies among employees at different organizational levels within the business (inter-business differences), and among employees working for different organizations (intra-business differences). Also, future work should analyze whether aspects of organizational culture (safety climate, shared values or beliefs) explains the degree of (mis)alignment of employees in terms of perceived safety. Second, future studies should evaluate whether safety experts' risk awareness is conditioned by factors related to the organization (safety climate or business culture) or to previous job experience as a construction worker or as safety expert. Third, our work is inherently connected with prior work based on the Resilience Engineering theory (e.g., Niskanen, 2018; Patriarca et al., 2018). In this sense, and building on Resilience Engineering postulates, specifically designed future research should evaluate whether organizational resilience is contingent to the interactions between individual actions and relations, as well as to organizational qualities resulting from the organization and subsequent performance of teams within the business. Finally, the geographic and industry specificity of the study calls for obvious caution when generalizing its findings. In this sense, future work should assess the determinants of perceived work safety in different industry sectors and in different geographic contexts to further validate the results of our study.

\section{Declaration of Conflicting Interests}

The authors declared no potential conflicts of interest with respect to the research, authorship, and/or publication of this article. 


\section{Funding}

The authors received no financial support for the research, authorship, and/or publication of this article.

\section{References}

Abad, J., Lafuente, E., \& Vilajosana, J. (2013). An assessment of the OHSAS 18001 certification process: Objective drivers and consequences on safety performance and labour productivity. Safety Science, 60, 47-56. https://doi.org/10.1016/j.ssci.2013.06.011

Arcury, T.A., Summers, P., Carrillo, L., Grzywacz, J.G., Quandt, S.A., \& Mills, T. (2014). Occupational safety beliefs among Latino residential roofing workers. American Journal of Industrial Medicine, 57, 718-725.

https://doi.org/10.1002/ajim.22248

Arcury, T.A., Summers, P., Rushing, J., Grzywacz, J.G., Mora, D.C., Quandt, S.A. et al. (2015). Work safety climate, personal protection use, and injuries among Latino residential roofers. American Journal of Industrial Medicine, 58(1), 69-76. https://doi.org/10.1002/ajim.22404

Argote, L., \& Miron-Spektor, E. (2011). Organizational Learning: From Experience to Knowledge. Organization Science, 22(5), 1123-1137. https://doi.org/10.1287/orsc.1100.0621

Baxendale, T., \& Jones, O. (2000). Construction design and management safety regulations in practice-Progress on implementation. International Journal of Project Management, 18(1), 33-40. https://doi.org/10.1016/S02637863(98)00066-0

Björk, P., Lindqvist, L., Poukkula, K., Ravald, A., West, B., \& Åhman, S. (2004). A theory of marketing-in-use in micro firms-Preliminary findings. Proceedings, Nordic Conf. on Small Business Research (NCSB), 10-12.

Boix, P., García, A.M., Llorens, C., \& Torada, R. (2001). Perceptions and experiences. Report prepared for the Institute for Sindical Trabajo, Ambiente, y Salud, Valencia, Spain (in Spanish).

Braithwaite, J., Wears, R.L., \& Hollnagel, E. (2017) Methods and solutions: reconciling work-as-imagined and work-as-done. In J. Braithwaite, R.L. Wears \& E. Hollnagel (Eds.). Resilient Health Care. Boca Raton: CRC Press.

Camerer, C.F., \& Lovallo, D. (1999). Overconfidence and excess entry: An experimental approach. American Economic Review, 89, 306-318. http://www.jstor.org/stable/116990

Caponecchia, C., \& Sheils, I. (2011). Perceptions of personal vulnerability to workplace hazards in the Australian construction industry. Journal of Safety Research, 42, 253-258. https://doi.org/10.1016/j.jsr.2011.06.006

De Carvalho, P.V.R., Righi, A.W., Huber, G.J., Lemos, C.D.F., Jatoba, A., \& Gomes, J.O. (2018). Reflections on work as done (WAD) and work as imagined (WAI) in an emergency response organization: A study on firefighters training exercises. Applied Ergonomics, 68, 28-41. https://doi.org/10.1016/j.apergo.2017.10.016

Christian, M.S., Bradley, J.C., Wallace, J.C., \& Burke, M.J. (2009). Workplace safety: a meta-analysis of the roles of person and situation factors. Journal of Applied Psychology, 94, 1103-1127. https://doi.org/10.1037/a0016172

Colton, D., \& Covert, R. (2007). Designing and constructing instruments for social research and evaluation. California: John Wiley \& Sons, Inc.

Das, A., Pagell, M., Behm, M., \& Veltri, A. (2008). Toward a theory of the linkages between safety and quality. Journal of Operations Management, 26, 521-535. https://doi.org/10.1016/j.jom.2007.06.005

European Agency for Safety and Health at Work (EU-OSHA) (2013). EU-OSHA Priorities for occupational safety and bealth research in Europe: 2013-2020. Luxembourg.

European Commission (2007). Improving quality and productivity at work: Community strategy 2007-2012 on health and safety at work. Communication from the Commission to the European Parliament, the Council, the European Economic and Social Committee and the Committee of the Regions, COM, 62. 
Fischhoff, B., Slovic, P., Lichtenstein, S., Read, S., \& Combs, B. (1978). How safe is safe enough? A psychometric study of attitudes towards technological risks and benefits. Policy Sciences, 9(2), 127-152.

https://doi.org/10.1007/BF00143739

Gierlach, E., Belsher, B.E., \& Beutler, L.E. (2010). Cross-cultural differences in risk perceptions of disasters. Risk Analysis, 30(10), 1539-1549. https://doi.org/10.1111/j.1539-6924.2010.01451.x

Grasmück, D., \& Scholz, R.W. (2005). Risk Perception of Heavy Metal Soil Contamination by High-Exposed and Low-Exposed Inhabitants: The Role of Knowledge and Emotional Concerns. Risk Analysis, 25(3), 611-622. https://doi.org/10.1111/j.1539-6924.2005.00628.x

Greene, W. (2003). Econometric analysis. New Jersey: Prentice Hall.

Griffin, M.A., \& Neal, A. (2000). Perceptions of safety at work: a framework for linking safety climate to safety performance, knowledge, and motivation. Journal of Occupational Health Psychology, 5, 347-358.

https://doi.org/10.1037/1076-8998.5.3.347

Gucer, P.W., Oliver, M., \& McDiarmid, M. (2003). Workplace threats to health and job turnover among women workers. Journal of Occupational and Environmental Medicine, 45(7), 683-690. https://doi.org/10.1097/01.jom.0000071508.96740.94

Hallowell, M. (2010). Safety risk perception in construction companies in the Pacific northwest of the USA. Construction Management and Economics, 28 (4), 403-413. https://doi.org/10.1080/01446191003587752

Hogarth, R.M., \& Karelaia, N. (2012). Entrepreneurial success and failure: Confidence and fallible judgment. Organization Science, 23(6), 1733-1747. https://doi.org/10.1287/orsc.1110.0702

Howard, M.E. (1983). The causes of war and other essays. Cambridge, MA: Harvard University Press.

Huang, Y.H., Verma, S.K., Chang, W.R., Courtney, T.K., Lombardi, D.A., Brennan, M.J. et al. (2012). Supervisor vs. employee safety perceptions and association with future injury in US limited-service restaurant workers. Accident Analysis \& Prevention, 47, 45-51. https://doi.org/10.1016/j.aap.2011.11.023

Hung, Y.H., Winchester, W.W. III, Smith-Jackson, T.L., Kleiner, B.M., Babski-Reeves, K.L., \& Mills, T.H. III. (2013). Identifying fall-protection training needs for residential roofing subcontractors. Applied Ergonomics, 44, 372-380. https:// doi.org/10.1016/j.apergo.2012.09.007

Juslin, P., Winman, A., \& Olsson, H. (2000). Naive empiricism and dogmatism in confidence research: A critical examination of the hard-easy effect. Psychological Review, 107, 384-396. https://doi.org/10.1037/0033-295X.107.2.384

Klayman, J., Soll, J.B., Gonzalez-Vallejo, C., \& Barlas, S. (1999). Overconfidence: It depends on how, what, and whom you ask. Organizational Behavior and Human Decision Processes, 79, 216-247.

https://doi.org/10.1006/obhd.1999.2847

Krueger, J.I., Acevedo, M., \& Robbins, J.M. (2005). Self as sample. In K. Fiedler \& P. Juslin (Eds.), Information sampling and adaptive cognition, 353-377. New York: Cambridge University Press.

Lafuente, E., \& Abad, J. (2018). Analysis of the relationship between the adoption of the OHSAS 18001 and business performance in different organizational contexts. Safety Science, 103, 12-22.

https://doi.org/10.1016/j.ssci.2017.11.002

Lafuente, E., Vaillant, Y., \& Rialp, J. (2007). Regional differences in the influence of role models: comparing the entrepreneurial process of rural Catalonia. Regional Studies, 41(6), 779-795.

https://doi.org/10.1080/00343400601120247

Long, J.S. (1997). Regression Models for Categorical and Limited Dependent Variables. Thousand Oaks, CA: Sage Publications.

Malmendier, U., \& Tate, G. (2005). CEO overconfidence and corporate investment. Journal of Finance, 60, 2661-2700. https://doi.org/10.1111/j.1540-6261.2005.00813.x 
Mearns, K., Flin, R., Gordon, R., \& Fleming, M. (1998). Measuring safety climate on offshore installations. Work Stress, 12(3), 238-254. https://doi.org/10.1080/02678379808256864

Mohamed, S., Ali, T.H., \& Tam, W. (2009). National culture and safe work behaviour of construction workers in Pakistan. Safety Science, 47(1), 29-35. https://doi.org/10.1016/j.ssci.2008.01.003

Moore, D.A., \& Healy, P.J. (2008). The trouble with overconfidence. Psychological Review, 115(2), 502-517. https://doi.org/10.1037/0033-295X.115.2.502

Neal, A., \& Griffin, M.A. (2006). A study of the lagged relationships among safety climate, safety motivation, safety behavior, and accidents at the individual and group levels. Journal of Applied Psychology, 91, 946-953.

https://doi.org/10.1037/0021-9010.91.4.946

Neale, M.A., \& Bazerman, M.H. (1985). The effects of framing and negotiator overconfidence on bargaining behaviors and outcomes. Academy of Management Journal, 28, 34-49. https://doi.org/10.2307/256060

Niskanen, T. (2018). A Resilience Engineering-related approach applying a taxonomy analysis to a survey examining the prevention of risks. Safety Science, 101, 108-120. https://doi.org/10.1016/j.ssci.2017.08.016

Patriarca, R., Bergström, J., Di Gravio, G., \& Costantino, F. (2018). Resilience engineering: Current status of the research and future challenges. Safety Science, 102, 79-100. https://doi.org/10.1016/j.ssci.2017.10.005

Perlman, A., Sacks, R., \& Barak, R. (2014). Hazard recognition and risk perception in construction. Safety Science, 64, 22-31. https://doi.org/10.1016/j.ssci.2013.11.019

Plous, S. (1993). The psychology of judgment and decision making. New York: McGraw-Hill.

Porru, S., Placidi, D., Carta, A., \& Alessio, L. (2006). Prevention of injuries at work: the role of the occupational physician. International Archives of Occupational and Environmental Health, 79(3), 177-192. https://doi.org/10.1007/s00420-005-0023-1

Portell, M., Gil, R.M., Losilla, J.M., \& Vives, J. (2014). Characterizing occupational risk perception: the case of biological, ergonomic and organizational hazards in Spanish healthcare workers. Spanish Journal of Psychology, 17(e51), 1-12. https://doi.org/10.1017/sjp.2014.55

Reisinger, Y., \& Mavondo, F. (2005). Travel anxiety and intentions to travel internationally: Implications of travel risk perception. Journal of Travel Research, 43(3), 212-225. https://doi.org/10.1177/0047287504272017

Rodríguez-Garzón, I., Lucas-Ruiz, V., Martínez-Fiestas, M., \& Delgado-Padial, A. (2014). Association between perceived risk and training in the construction industry. Journal of Construction Engineering and Management, 142(11), 04014095. https://doi.org/10.1061/(ASCE)CO.1943-7862.0000960

Rundmo, T. (1996). Associations between risk perception and safety. Safety Science, 24(3), 197-209. https://doi.org/10.1016/S0925-7535(97)00038-6

Rundmo, T. (2000). Safety climate, attitudes and risk perception in Norsk Hydro. Safety Science, 34(1-3), 47-59. https://doi.org/10.1016/S0925-7535(00)00006-0

Savolainen, P.T., Mannering, F.L., Lord, D., \& Quddus, M.A. (2011). The statistical analysis of highway crash-injury severities: a review and assessment of methodological alternatives. Accident Analysis \&o Prevention, 43(5), 1666-1676. https://doi.org/10.1016/j.aap.2011.03.025

Sjöberg, L. (2000). Factors in risk perception. Risk Analysis, 20 (1), 1-12. https://doi.org/10.1111/0272-4332.00001

Soll, J.B., \& Klayman, J. (2004). Overconfidence in interval estimates. Journal of Experimental Psychology: Learning, Memory, and Cognition, 30(2), 299-314. https://doi.org/10.1037/0278-7393.30.2.299

Starren, A., Hornikx, J., \& Luijters, K. (2013). Occupational safety in multicultural teams and organizations: A research agenda. Safety Science, 52, 43-49. https://doi.org/10.1016/j.ssci.2012.03.013

Woods, D.D. (2015). Four concepts for resilience and the implications for the future of resilience engineering. Reliability Engineering \& System Safety, 41, 5-9. https://doi.org/10.1016/j.ress.2015.03.018 
Zimolong, B., \& Trimpop, R. (1998). Risk perception. Encyclopedia of occupational health and safety, ILO, Geneva, Switzerland.

Zohar, D. (2002). Modifying supervisory practices to improve subunit safety: a leadership-based intervention model. Journal of Applied Psychology, 87(1), 156-163. https://doi.org/10.1037/0021-9010.87.1.156

Zohar, D. (2003). Safety climate: conceptual and measurement issues. In: Quick, J.C., \& Tetrick, L.E. (Eds.). Handbook of Occupational Health Psychology (123-142). American Psychological Association, Washington, DC.

Zohar, D., \& Luria, G. (2005). A multilevel model of safety climate: cross-level relationships between organization and group-level climates. Journal of Applied Psychology, 90(4), 616-628. https://doi.org/10.1037/0021-9010.90.4.616

Journal of Industrial Engineering and Management, 2018 (www.jiem.org)

\section{(c) $(1) \otimes$}

Article's contents are provided on an Attribution-Non Commercial 4.0 Creative commons International License. Readers are allowed to copy, distribute and communicate article's contents, provided the author's and Journal of Industrial Engineering and Management's names are included. It must not be used for commercial purposes. To see the complete license contents, please visit https://creativecommons.org/licenses/by-nc/4.0/. 